“Ocean Margin Systems" - G. Wefer et al. (eds) - Springer Verlag 2001

\title{
SEABED CLASSIFICATION AT OCEAN MARGINS
}

\author{
Philippe BLONDEL \\ Department of Physics; University of Bath; Bath BA2 7AY, UK
}

\begin{abstract}
Ocean margins have become the focus of most geophysical and environmental surveys, because of their economic, scientific and oceanographic significance. These surveys deliver increasingly larger volumes of data, acquired by many types of techniques and sensors. Despite its importance, most of this data is still interpreted visually and qualitatively by skilled interpreters. Human interpretation is timeconsuming and difficult to standardise; and, in certain conditions, it can be error-prone. Current research in data processing is shifting toward computer-based interpretation techniques, and in particular seafloor classification. After a brief review of the main characteristics of ocean margins, the different notions of classification will be presented, along with the desired aims. They will be followed with a review of non-acoustic and acoustic (mainly sonar) classification techniques, supplemented with actual examples when applicable. Seabed classification, in general and at ocean margins, is fast becoming a major tool in seafloor surveying and monitoring, and the last section will assess the latest tendencies, and the technical developments that can be expected in the near future.
\end{abstract}

\section{INTRODUCTION}

Scientific advances of the last decades have revealed the extreme importance of ocean margins in all areas of human endeavours. Seafloor exploration has revealed their sheer size and variety. Oceanographic studies have revealed their importance for global ocean circulation. Marine and terrestrial geology have revealed their role in the generation and propagation of often catastrophic tsunamis. And, in general, ocean margins have proved important in all spheres of human activity: political (Exclusive Economic Zones), industrial (oil and gas exploration, communications), ecological (fisheries, environmental assessments), military (potential or actual theatres of operation), etc.

The ocean margins are very varied and complex environments, harbouring a multitude of variations in geology (sedimentation, volcanism, tectonics), and acting as markers of chemical, biological and human activity (coral reefs, pollution, etc.). Many portions of ocean margins around the world have not been mapped yet, either in general or in detail, and more areas still need to be surveyed and monitored. Technological progress ensures that the number of instruments available for exploring, surveying and monitoring increases steadily. The same is true of their resolution, and in general of the amount of (often digital) data that these instruments generate. Traditional, qualitative interpretation by skilled specialists is time-consuming and difficult to standardise. The presence of knowledgeable interpreters with the appropriate expertise is also not guaranteed in all marine operations. This is why current research efforts are turning toward computer-based interpretation techniques. These classification techniques must supplement the raw data with quantitative results going as far as possible beyond what is achievable through human interpretation.

Seabed measurements are actually made at scales varying from the millimetre to the kilometre, with varying degrees of penetration below the seafloor. This data is acquired at sea in often complex and limiting conditions, with a bewildering variety of sensors, ranging from acoustics to radioactivity. Each will require a different type of 
classification technique, which most often than not cannot be transferred to another domain or needs to be developed specifically. The present article aims at providing an overview of these techniques, how they work and what they achieve.

The initial description of the different types of seafloor structures at the ocean margins will be followed by the definition of seabed classification, its aims and its means. This will be followed by a review of non-acoustic and acoustic classification techniques. Each will be supplemented with actual examples, and pointers to the appropriate references detailing these techniques and their achievements.

This article does not pretend to be an exhaustive list of all possible seabed classification techniques, using all possible instruments. Some techniques have been left out, either voluntarily (untested or inconclusive techniques) or involuntarily. A complete treatment of past, present and future seabed classification techniques would require a complete book, and only the main domains will be presented here.

Seabed classification, in general and at ocean margins in particular, is fast becoming a major tool in seafloor surveying and monitoring. The last section will thus assess the latest advances, the technical developments that can be expected in the near future, and their likely impacts.

\section{OCEAN MARGINS AND SEABED CLASSIFICATION}

\subsection{General setting of continental margins}

Ocean margins are the site of, and influence many aspects of our socio-economic activities. In addition, they form a major area of biodiversity and habitat of the world's ecology. The Exclusive Economic Zones of most industrialised countries occupy continental margins, from which they derive an important portion of their wealth. Hydrocarbon exploitation is presently concentrated on continental shelves (for example in the North Sea or the Gulf of Mexico), but is steadily moving over the shelf edge into deeper waters. The world's largest fish reserves are also located on the continental margins, and their management often proves politically and economically difficult. Therefore, a detailed knowledge of the ocean margins is of eminent importance, as for example slope failures and the resultant mass-movement flows, are capable of destroying marine installations and submarine cables, and even of generating tsunamis.

Recent environmental studies have also shown the importance of a more complete and detailed knowledge of continental margins, such as for global climate studies and modelling of the carbon cycle, for exchange processes at the shelf edge, as well as for studies of anthropogenic inputs. These may provide a direct link to coastal pollution, and may reflect the off-shore dumping of harmful chemical products in poorly known areas that were wrongly assumed deep and stable enough.

The continental margins can be broadly divided into the continental shelf close to the coast (down to about $200 \mathrm{~m}$ on average), the adjacent and somewhat steeper continental slope (down to $3000 \mathrm{~m}$ ), and the continental rise at the limit with the abyssal plains (Figure 1). The continental shelf is a relatively flat area (slopes less than 1:1,000, low local relief). Underlain by continental crust, it is also remarkably shallow; generally less than $250 \mathrm{~m}$. Depending on the regional geological setting, the shelf will extend from a few (tens of) kilometres (near subduction zones, for example) to several hundreds of kilometres (near passive margins) away from the coastline. The 
continental shelves are areas of input of (sometimes very large) quantities of sediments by the rivers, sometimes even at large distances from land (e.g. the Indus, the Amazon or the Yangtze rivers). Also on the shelves, pelagic settling takes place, and depending on local tidal, wave and current conditions, these particles may settle either on the shelf or be transported over the shelf edge. During this transport, and quantified over time, large volumes of sediments ultimately settle on the continental slope. This rapidly descending area ranges in depth between ca. $200 \mathrm{~m}$ and 3,000 m. Another means of transport of particles from the shelf over the slope and into the deep sea is through channels and canyons, bringing the sediment far out into the abyssal plains. In the Western Atlantic, canyons extend for several hundreds of kilometres as tightly sinuous channels with no tributaries, whereas in the Southeastern Pacific, they meander on longer distances and leave behind abandoned channel segments (see Blondel and Murton, 1997, for examples). Locally, sediments are contained within contourite bodies (sediment drifts) that have formed by sedimentation under influence from currents following the bathymetric contours, sometimes with sediment or sand waves on their flanks (e.g. Blondel and Murton, 1997).

Because of the occasionally steep slopes, and in combination with for example fast sedimentation, the slopes may become unstable, and earthquakes or minor sea-level changes can trigger their collapse, creating large-scale submarine slides and slumps (the larger ones producing internal waves or tsunamis). In combination with particles settling from the pelagic zone, sediments are carried over the slope to the continental rise. This physiographic province marks the limit between the continental margins and the abyssal plains. Deeper than 3,000 m, the continental rise can go down to $6,000 \mathrm{~m}$ (as in the North Atlantic). The more prominent structures at the continental rise are the distal deep-sea fans, lobes and sediment channels marking the outer limits of canyon-influenced sedimentation. In case of large-scale slope failures (e.g. Storegga slide or Grand Banks earthquake), this may also lead to transport of large amounts of slope sediments forming local bulges.

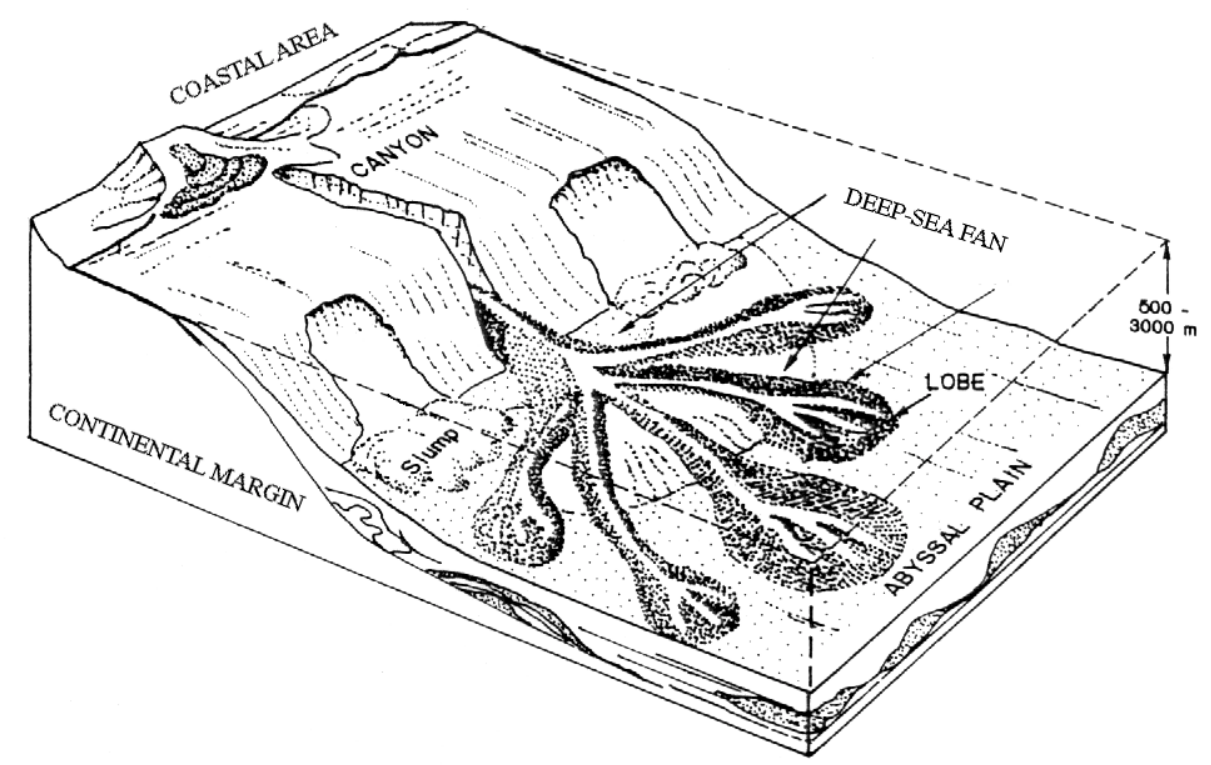

Figure 1. Morphological diversity of continental margins. 


\subsection{Complex and varied environments}

Continental margins are the geological regions with the largest depth range, and with a great diversity of morphological structures. Figure 1 shows only a couple of them; from the sediments input by rivers, caused by erosion of the continent, and biogenic carbonate deposits in the coastal area and at the shelf and shelf edge (in tropical areas), to the junction with the flat, comparatively featureless abyssal plains. The inventory of all possible structures goes beyond the remit of this article, and much of it is already covered in reference books (e.g. Blondel and Murton, 1997; Stoker et al., 1998, and references therein).

To grossly simplify what is truly a complex environment, the sediments coming from the continents themselves are deposited in the coastal area (Figure 1), forming largescale sedimentary structures such as estuaries, deltas and fans. A large portion of the accumulated sediment moves downslope, transported through large slides, often called debris slides, or along narrow channels merging into submarine canyons (Figure 1). Not all submarine canyons look alike. Some canyons just cut into the continental slope, while others may extend far onto the continental rise.

Large sediment accumulations are usually unstable, and can move downslope as slumps, slides, and debris flows, leaving scars on the seafloor and the marks of downslope transportation and deposition of sediments. Factors known to influence these catastrophical events include loading or oversteepening of slopes, underconsolidation of sediments due to rapid sedimentation, earthquakes, gas build-up and sea-level changes. Mass-movement deposits are often called debris, and include mixed lithologies of muds, clays and sands, with inclusions of pieces of hardrock, pebbles and boulders, with sizes ranging from decimetres to several hundreds of metres (e.g. Blondel and Murton, 1997; Stoker et al., 1998).

Tectonic structures (such as faults and folds) and volcanic structures below the seabed or emerging above, may also be found. When still intact, these volcanoes look very much like their counterparts at spreading centres. Their dimensions need to be more important (several kilometres), to emerge above the sediment layers. Other structures, discovered in the last decade, are actively forming mud volcanoes, or mud mounds, often in association with local gas seeps, or gas hydrate below the seabed, and often in tectonically active regions. These are interesting structures, as potential traps for hydrocarbons, and because they can create important modifications of the seafloor, which are potential hazards to telecommunication cables and pipelines.

Other structures visible on continental shelves and margins are pockmarks, associated with past or present seepage of gases and fluids. Most pockmarks are approximately circular in plan, but there is a considerable variety in shapes and sizes, as they are active features (e.g. Blondel and Murton, 1997). Because of their origin and of their locations (often in close relationship with hydrocarbon reservoirs in the deeper seabed underneath), pockmarks generate a considerable interest in offshore industries. This interest is enhanced by the consequences pockmarks may have on the stability of offshore platforms and the security of drilling exploration. Catastrophic gas escapes can form large, deep pockmarks in very short periods of time. In one occurrence, the gas blowout at a depth of $240 \mathrm{~m}$ reached to the surface, and instabilities led to the abandonment of a neighbouring drilling platform.

Structures related to local brine accumulation can be found in various environments, and manifest themselves as bottom depressions filled with hypersaline water. Brine pools have been particularly well documented on the Mediterranean Ridge and in the Gulf of Mexico; the Mediterranean ones are thought to result from the rapid 
dissolution of evaporites in the Late Miocene. Brine lakes and pools are uncommon features on the seafloor, and have been often discovered in the proximity of mud volcanoes or of important faults (e.g. Blondel and Murton, 1997). Brine pools also present a biological interest, since the recent discovery of deep-sea chemosynthetic communities and faunal assemblages.

Biological activity at continental margins can manifest itself in many ways. For seabed classification, the organisation of biota in large-scale structures, such as slumps of large algae, local accumulations of dead and living plants, or formation of carbonate structures, reefs and deposits, are all of considerable importance. In shallower waters, coral structures are also visible. Halimeda mounds (bioherms), composed of clustered dead and living plants, have for example been documented on the western Indian continental shelf, in water depths close to 90 metres. They can be tens of metres high and several hundred metres long. Bioherms on the shelf edge appear more linear, whereas deeper bioherms generally assume mound-like morphologies (cf. Blondel and Murton, 1997). Linear algal ridges and cold-water coral carbonate mounds, sometimes aligned along tectonic faults and fault structures, have also been documented along the Eastern Atlantic margin, from Spain to Norway, in water depths ranging from 300 to $1200 \mathrm{~m}$.

\subsection{Seabed classification}

Continental margins appear therefore as a strongly variable environment. Confronted with many and diverse types of (sometimes new) structures, often arranged in complex patterns, the interpreter of marine data needs classification techniques. But what is seabed classification? A rapid search through the scientific and technical literature shows many different definitions of the word "classification". These definitions are often blurred by commercial hype, and by the need to communicate between different disciplines (e.g. image processing, marine geology, underwater acoustics) with different vocabularies. These semantic differences can be quite confusing. One usually distinguishes three different stages: segmentation, classification and characterisation.

Segmentation comes from the image processing world, and defines the partition of an image into several regions with different characteristics. The image may come from any source (satellite image, medical image etc.), and the partitions of the image are not definitely interpreted. They just share the same numerical characteristics, and are generally labelled only with letters or numbers.

Classification goes one step further. Classification recognises these different regions as distinct physical entities, even if a physical feature can correspond to several partitions (e.g. "mud = partition $1 \&$ partition 2"), or a partition can correspond to several physical features (e.g. "corals and aggregated pebbles").

Characterisation is the next step, where the regions recognised in the images or in the maps correspond to definite characteristics, physical (e.g. particular shear wave attenuation), chemical (e.g. oil slick or metallic object), geological (e.g. fine-grained silt), or biological (e.g. coral mound).

Notwithstanding confusions between scientific disciplines with different jargons, one can see how a new system can quickly be marketed as achieving "seafloor characterisation", even if it only performs "seafloor segmentation", as this makes it more likely to attract potential customers. For the sake of simplicity, the definition of seabed classification adopted here will be broader, and encompass both classification 
per se, and characterisation. The techniques and systems presented in the next two sections have been selected because they could achieve at least a basic recognition of the type of seafloor surveyed, or because they could identify a set of seabed intrinsic characteristics (e.g. grain size, porosity, density) from which the type of seafloor could be recognised. The capability and spatial coverage offered by the different tools will vary, and they have been regrouped into two categories: non-acoustic systems and acoustic systems (by far the most present in the literature).

\section{NON-ACOUSTIC SEABED CLASSIFICATION}

\subsection{In-situ seabed analysis}

The most simple and traditional way of characterising the seabed is through the taking of samples and their on-board analysis by skilled interpreters. Historically, it was by using line soundings that the first samples of the deep ocean floor were collected for scientific purposes. Dredging has not evolved much since the nineteenth century: a strong welded steel frame, holding open a sturdy bag of steel chain, is attached through hinged attachment arms to the heavy steel wire that lowers the dredge to the seafloor. The dredge is towed directly on the bottom, and the steel frame of this rudimentary device pulls out portions of the seafloor. Its positioning on the seafloor is much more precise now than it was in the nineteenth century, owing to GPS and transponder technology. There are different types of dredges (e.g. Juteau and Maury, 1999), but even the most adapted dredge might bounce off obstacles (e.g. rocky outcrops) or scrape the seafloor without sampling it. Furthermore the samples collected are in complete disorder and their precise location along the dredge track is impossible to know.

Coring methods are commonly used for sampling still-soft and water-saturated oceanic sediments. There are many types of coring techniques, but all enable the sampling of a complete cross-section of sediments, and its laboratory analysis for different properties, using geoacoustics, X-ray tomography, microscopic analysis etc. (e.g. Orsi et al., in Pace et al., 1997; Balsam et al., 1999). Cores can be very precisely located on the seafloor, and recent use of video data adds to the final interpretation, in particular by showing how each core is representative of the area. The problem is that cores are very localised (a few centimetres or tens of centimetres in diameter), and usually very time-consuming and/or expensive to acquire. This becomes even more true as one moves to the deeper parts of the continental margins.

Free-fall instruments have also been designed for rapid assessment of specific geoacoustic and geotechnical parameters. Penetrometers dropping through the water column penetrate the seabed to different depths and at different rates depending on the geometry, mass, and impact velocity of the probe, and on the shearing strength of the sediment. If the physical dimensions and terminal velocity of the probe are fixed, it is possible to infer the shearing strength and certain other properties based on an analysis of the deceleration signature, compared with a database compiled from tests on different types of sediments. This is the approach used by Stoll and Akal (1999) for the XBP (eXpendable Bottom Probe), now available commercially. Rosenberger et al. (1999) developed a similar instrument, measuring the resistivity of the seafloor. Longer stations on the seafloor are possible with complete instrumentation platforms, which can take more time-demanding measurements of the seabed properties. This is for example the case of ISSAMS, the In Situ Sediment geoAcoustic Measurement System developed by Barbagelata et al. (1991), which measures compressional and 
shear speed and compressional attenuation. Like cores, these tools are very localised and time-consuming.

Direct sampling by manned submersibles or Remotely-Operated Vehicles (ROVs) is more adaptable and selective. Recent technological and engineering advances allow to use many instruments simultaneously, even at large depths. For example, the German Ministry for Research and Technology is developing a ROV equipped with instruments for localizing and analysing chemical pollutants in the water column and on the seafloor. These instruments include a lidar (laser and fluorometre), an acoustic sensor for measuring the acoustic impedance of the seabed, a membrane induction/gas chromatograph/mass spectrometer, and a quartz microbalance sensor array (Harsdorf et al., 1998). But such sampling is even more time-consuming and expensive, and submersible constraints limit greatly the amount of samples that can be taken.

\subsection{Optical seabed classification}

Very often now, manned and unmanned dives are constantly recording video and still imagery. These images are interpreted and quantified with traditional image processing techniques (e.g. Lebart et al., 2000), as can be used for satellite imagery (e.g. feature-space classification). The general type of seafloor may be identified, even from complex images (Figure 2), but the other characteristics of the seabed remain inaccessible. The conditions in which the images are acquired are often causing problems: inadequate and variable lighting (Figure 2, left); unaccounted variations in the water column inside the field of view (e.g. shimmering), etc. Standard video cameras are also often unsuitable for seafloor imaging in case of high turbidity. Furthermore, pools of chemicals on sediment can hardly be seen on video images taken from above. Especially on coarse-grained sediments, their contours follow the ground, so that the low gradient of the index of refraction does not provide sufficient contrast.
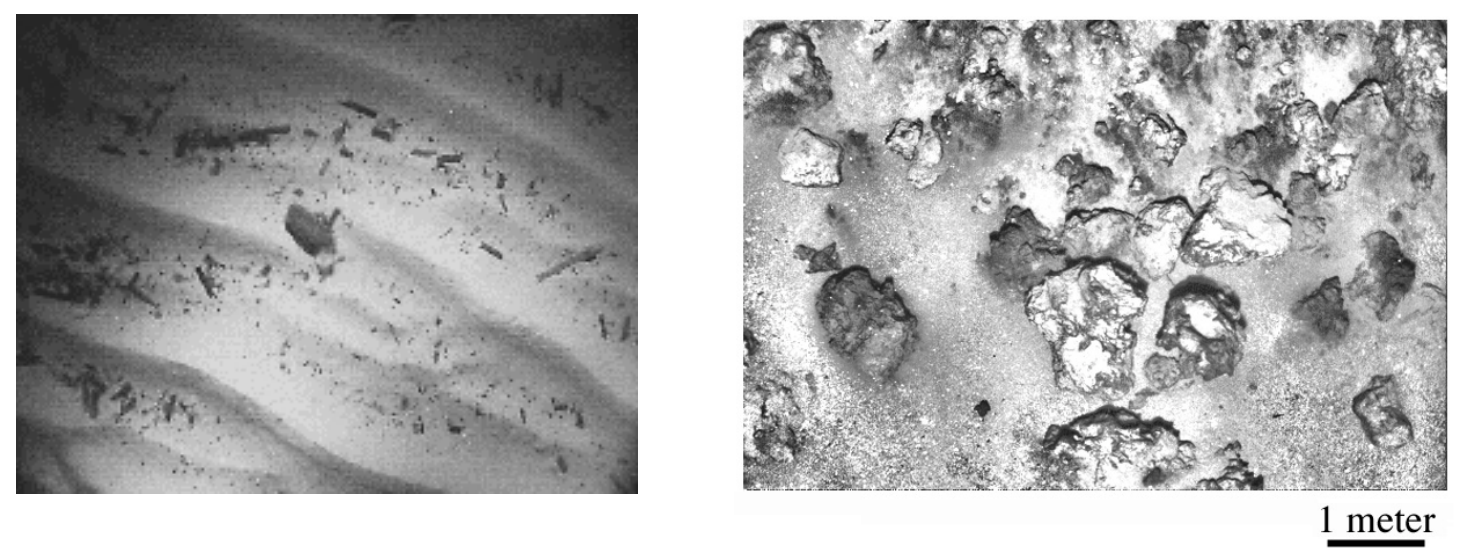

Figure 2. Comparison of a normal image (left) of sandy ripples, and a high-definition digital still image of sulphide rubble, taken from directly above (right).

(C) NATO/SACLANTCEN (left) and (C WHOI (right).

Laser-based techniques offer the advantage of constant, quantifiable illumination, and independence from all but the most severe disturbances in the water column. Laser line-scan systems, such as the Raytheon Model LS4042, sweep the seafloor with a pencil-thin laser beam, using a mechanism similar to the "push-broom" device of Earth-orbiting satellites. The reflected light is analysed, and the use of different filters yields multi-spectral images (and access to all the relevant classification techniques 
developed for satellite imagery). The narrow laser beam allows images to be acquired at distances three to four times that possible with conventional imaging systems. The emergence of high repetition solid state blue-green lasers and the latest developments in fast electronics provide new possibilities, although the operational range remains determined by the red channel (more attenuated in water). Originally designed to identify mines and mine-like objects in the shallow-water littoral environment, this and other similar systems are now used for the identification of anthropogenic materials and biological targets on the seafloor (Coles et al., 1998). Polarisation signature aids in material discrimination and identification, but the applications presented have not broached geological objects yet. Compared to classic, optical imagery, these laser systems can sweep further from the ROV or submersible, and cover substantially wider portions of the seabed. Airborne laser bathymetry, with systems like SHOALS (Scanning Hydrographic Operational Airborne Lidar), cover even wider strips, much faster. But these tools are limited to the shallowest parts of the continental shelf (Irish and Lillycrop, 1999), and their applications for seabed characterisation have not been assessed yet.

\subsection{Using the seabed radioactivity}

An interesting approach has been tested at sea by Noakes et al. (1999) and de Meijer et al. (2000), using the measurement of naturally occurring radionuclides to distinguish different types of seabeds. All natural materials incorporate some radioactive substances. The elements ${ }^{40} \mathrm{~K}$, and the decay products of ${ }^{232} \mathrm{Th}$ and ${ }^{238} \mathrm{U}$ emit $\gamma$ radiation. This $\gamma$ radiation is characteristic of the radionuclides and should therefore be detectable with scintillation detectors. The concentration of radionuclides in sediments depends on its size, its origin, and its mineral composition. These concentrations are usually very low, but still measurable with state-of-the-art equipment. According to de Meijer et al. (2000), mud shows more radioactivity per unit mass than sand or gravel. Sediments originating from granites are more radioactive than the weathering products of basalt. In addition, sediments occasionally also contain radionuclides released by anthropogenic processes (e.g. fertiliser production). Each type of seafloor, sedimentary or not, should therefore exhibit a distinctive radioactive signature.

The implementation by de Meijer et al. (2000) led to the Multi-Element Detector system for Underwater Sediment Activity (MEDUSA), based around a highly sensitive scintillation crystal encased in a watertight casing. MEDUSA is towed over the bottom at speeds of about $2 \mathrm{~m} / \mathrm{s}$ (ca. 4 knots), and the $\gamma$ rays emitted by the seabed are measured at 10-second intervals. Radioactivity concentrations are analysed in real time, using calibration points from a couple of samples taken at the beginning of the survey. The applications presented by de Meijer et al. (2000) include the mapping of mud concentrations in a dumping site $20 \mathrm{~km}$ northwest of Rotterdam Harbour (for an area of $15 \times 10 \mathrm{~km}$ ), and a high-resolution sand/mud map of the Hollandsch Diep (for an area of $20 \times 3 \mathrm{~km}$ ).

Radioactive characterisation of the different types of seabeds is accurate and relatively fast. However, the method has been tried only in shallow waters (up to $100 \mathrm{~m}$ with the GIMS/CS ${ }^{3}$ system of Noakes et al. (1999)), and both technological and scientific developments may be needed for use in deeper waters such as on continental margins. And this approach, like many others, provides information only for the small portion of seafloor directly below the instrument. This is not the case of acoustic techniques, which either penetrate the seafloor or image wide portions of the seafloor each time. 


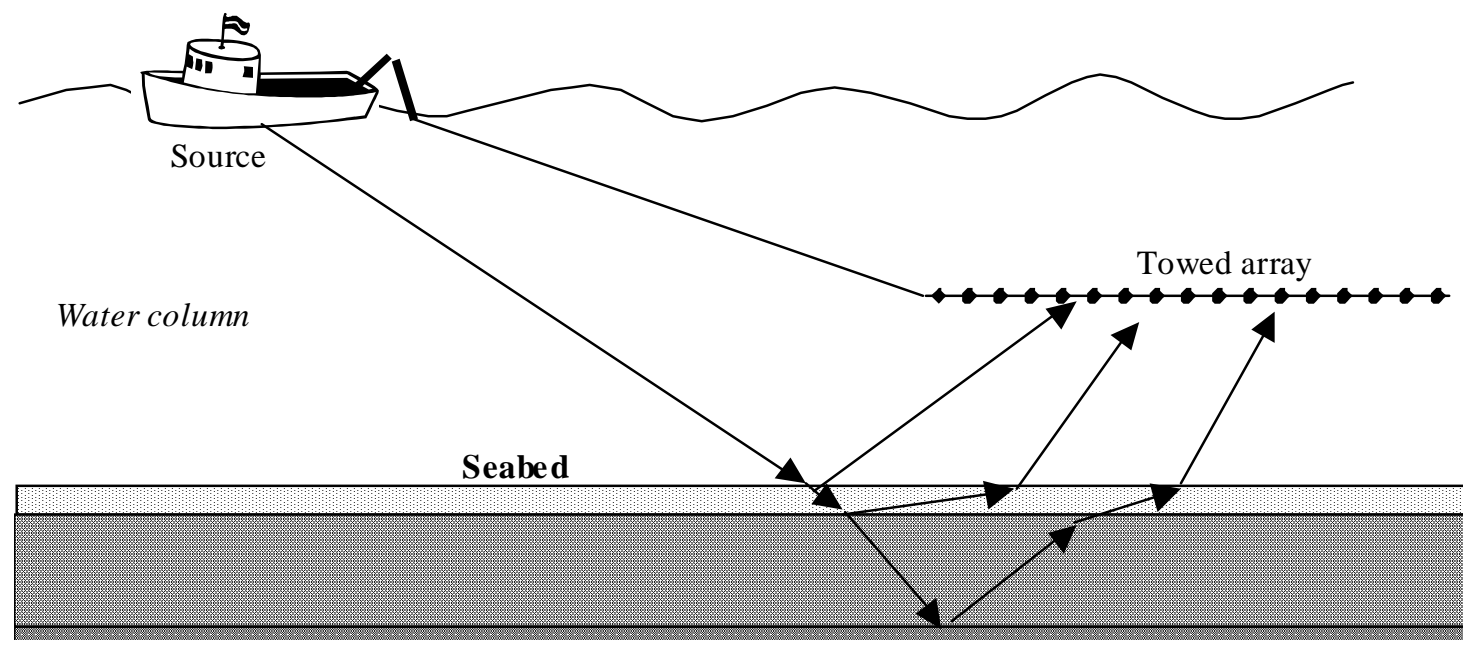

Figure 3. Principle of seismic surveys. The acoustic signal transmitted by the source is reflected by the different sediment layers, and recorded on the hydrophones positioned on the array towed at some distance behind the ship.

\section{ACOUSTIC SEABED CLASSIFICATION}

\subsection{Seismic seabed classification}

Seismic surveying is used to get information about the region immediately below the seafloor. Varied acoustic energy sources can be used: air or water guns, boomers, sparkers, dynamite or other explosives (e.g. Telford et al., 1990; Juteau and Maury, 1999). These sources usually transmit at frequencies between $10 \mathrm{~Hz}$ and several hundred Hz. After propagating through the water column, the acoustic wavefronts penetrate the sedimentary layers or the hard rocks below the seabed. They are reflected or refracted by geological discontinuities, and some of the energy returns back toward the surface. They are recorded by one or, more often, several receivers towed behind the survey vessel (Figure 3). Mono-channel seismic reflection provides a good resolution for shallow penetration, whereas multi-channel seismic reflection provides a variable resolution, but deeper penetration. Seismic refraction techniques are used to study the deepest structures, usually with two ships carrying out long seismic profiles, or using one ship and a buoy. Because the present article focuses on the seabed itself, only seismic reflection techniques will be considered.

Figure 4 shows a typical seismic profile, collected on the outer edge of a continental shelf. This profile shows the bathymetry along the survey line, expressed as the time taken for the sound waves to reach back to the receivers. It also shows the reflections from the first sediment layers below the seabed. The profile covers approximately 5 kilometres of seafloor, imaged to a depth of approximately 30 metres (with a vertical exaggeration of 28). Traditional analysis includes the picking of the "seismic horizons", i.e. the different layers or targets, and their interpretation as different geological features (e.g. Telford et al., 1990). This method is fraught with difficulties, especially as some of the seismic structures might be poorly contrasted, or buried in acoustic noise. It is also inherently qualitative, and does not provide much more than 
basic information about the seafloor characteristics. It works best when used in conjunction with information from direct sampling (coring, drilling).

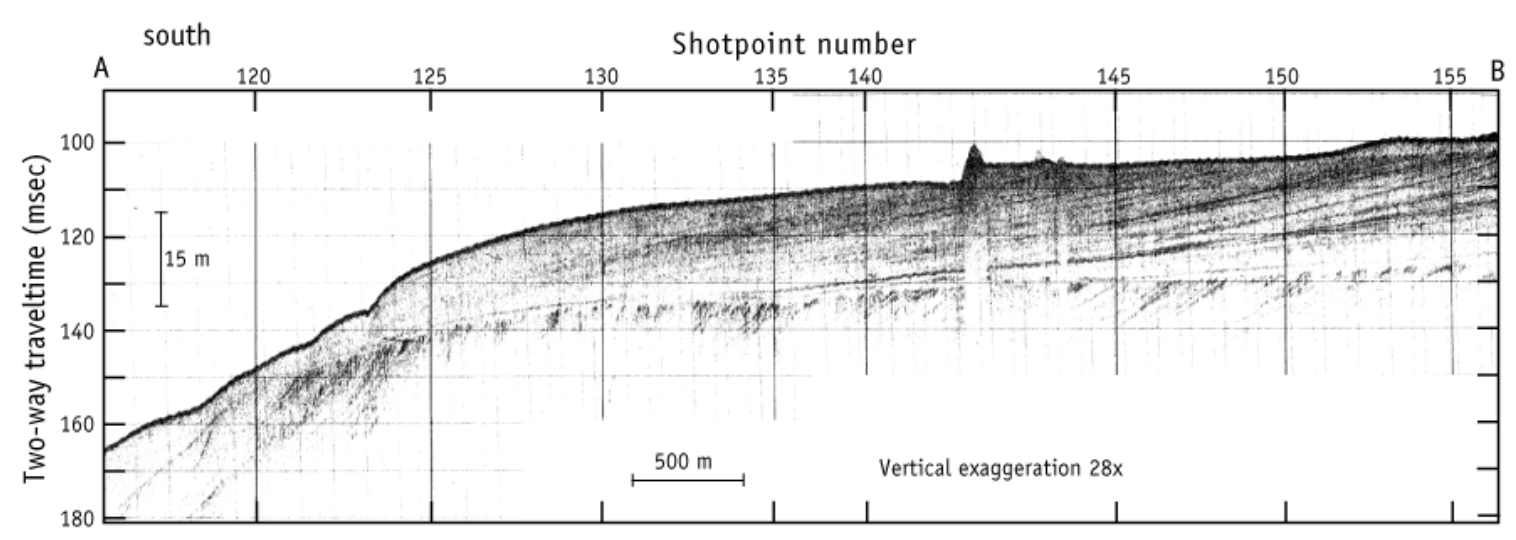

Figure 4. Portion of a seismic profile on the outer edge of the Mississippi ontinental shelf. From QuarterDeck Online, (www-ocean.tamu.edu/Quarterdeck/1998/3/sagerprofile.html)

(C) Department of Oceanography; Texas A\&M University.

Werby et al. (1986) addressed this problem using beamforming of the signals received by each hydrophone in the array, and direct inversion techniques. They use the fact that the propagation of seismo-acoustic modes at low frequencies is governed by the geophysical properties of the seabed (including $\mathrm{P}$ - and S-wave velocity and attenuation, density, and layer thickness). An appropriate measure of the signals reflected from the seafloor (or just beneath) might then indicate its general acoustic character. As presented, their method is restricted to shallow water depths (ca. $100 \mathrm{~m}$ ), and a spatial resolution of the order of a few wavelengths (for a frequency of $50 \mathrm{~Hz}$, the acoustic wavelength is $30.8 \mathrm{~m}$ ). It will therefore provide only a rough idea of the overall characteristics of the seafloor.

Davis et al. (in Pace et al., 1997) use a different technique to construct maps of the relative seabed reflectivity strength and shot-to-shot reflectivity variance. The acoustic source is a surface-towed boomer. The raw data from each hydrophone in the towed array is processed by detrending and correcting for geometrical spreading. A "swell" filter is then applied to remove the effects of water-wave motion. This enhances the lateral continuity of the subsurface layering. In the next stage, the amplitude envelope trace is calculated, and used for the detection of the seafloor and direct wave. The amplitude envelope trace is computed by convolving the absolute values of the original data trace with a rectangular window as long as the acoustic pulse. Bottom detection is then achieved with a simple time-delay threshold, robust and computationally efficient. The first peak after bottom detection is taken as the relative bottom reflectivity strength. The bottom reflectivity variance is calculated over windows of 40 shots. The maps of these two parameters allow more quantitative descriptions of the structures detected. Calibration data (from cores analysed onboard) allows correlating relative seabed reflectivity values to absolute bottom reflection coefficients, using empirical relationships from the literature. These coefficients can in turn be inverted to produce maps of the bulk density, porosity and mean grain size of the seabed sediments. Davis et al. (in Pace et al., 1997) were thus able to recognise different types of seabed, including coarse-grained ripples, glacial till or outcropping bedrock. These results were validated with independent groundtruthing from cores and grab samples. 
Some other approaches (e.g. Liu and Fu, 1982; Simaan, 1998) consider the twodimensional seismic sections as images in their own right, and apply traditional image processing techniques to characterise the seismic units. These techniques are similar to the ones used for optical images (cf. Section 3.2) or sidescan images (cf. Section 4.3). They can use a priori information about what the seismic structures should look like (e.g. Liu and Fu, 1982), or local statistical descriptors of the seismic record (e.g. Simaan, 1998). Although they do not seem to have been incorporated into the major seismic analysis software, these approaches are interesting for the sub-surface applications. But they are of limited interest for the water-seabed interface, about which they give little or no information.

The extraction of physical/geotechnical information from the digital seismic reflection response is a domain of on-going research. But seismic data is limited spatially, as it gives information about the seabed directly below the survey lines only, and no information athwartship. The solution is to survey along closer lines, creating a denser grid. The reflections can be treated as a volume, rather than a profile, so that the analyst can look at the data from many angles in three dimensions (e.g. Kidd, 1999). Many commercial software exist for this purpose, such as EarthVision (Durham, 1999) or VoxelGeo (Kidd, 1999), but their classification routines are mostly semiquantitative. The other problem is that three-dimensional seismic data is very expensive to acquire, and estimated to cost around $\$ 1,000,000$ for an area of $30 \mathrm{~km}^{2}$, which leaves 3-D seismics out of reach of most academic institutions.

\subsection{Echosounder-based techniques}

Echo-sounders are the most simple acoustic systems to use. They transmit a single beam, oriented toward the ship's nadir (Figure 5). They generally use low-frequency signals $(<20 \mathrm{kHz})$ transmitted in short pulses $(<2 \mathrm{~ms})$. The first return from the seabed corresponds to the point closest to the ship, and the next returns correspond to points further away, as the sound cone spreads. If the seabed is rough, the echo will continue longer, returning from wider angles. The echo begins with a steep edge, due to normal backscattering enhanced by the maximal response of the transducer around its beam axis. The echo then follows with an overall decrease, due to increasing incident angles and to the lower portions of the directivity pattern. Secondary lobes may sometimes be observed, and, if the conditions are adequate, second returns (after reflection on the sea surface) might be recorded as well.

The size of the echosounder footprint is a function of the beamwidth and the water depth. As with all acoustic signals, the return from the seabed will be affected, in decreasing order of importance, by the local geometry of the sensor-target system (angle of incidence of the beam, local slope, etc.), the morphological characteristics of the surface (e.g. micro-scale roughness) and its intrinsic nature (composition, density, relative importance of volume vs. surface diffusion for the selected frequency) (Figure 6; Blondel and Murton, 1997). 


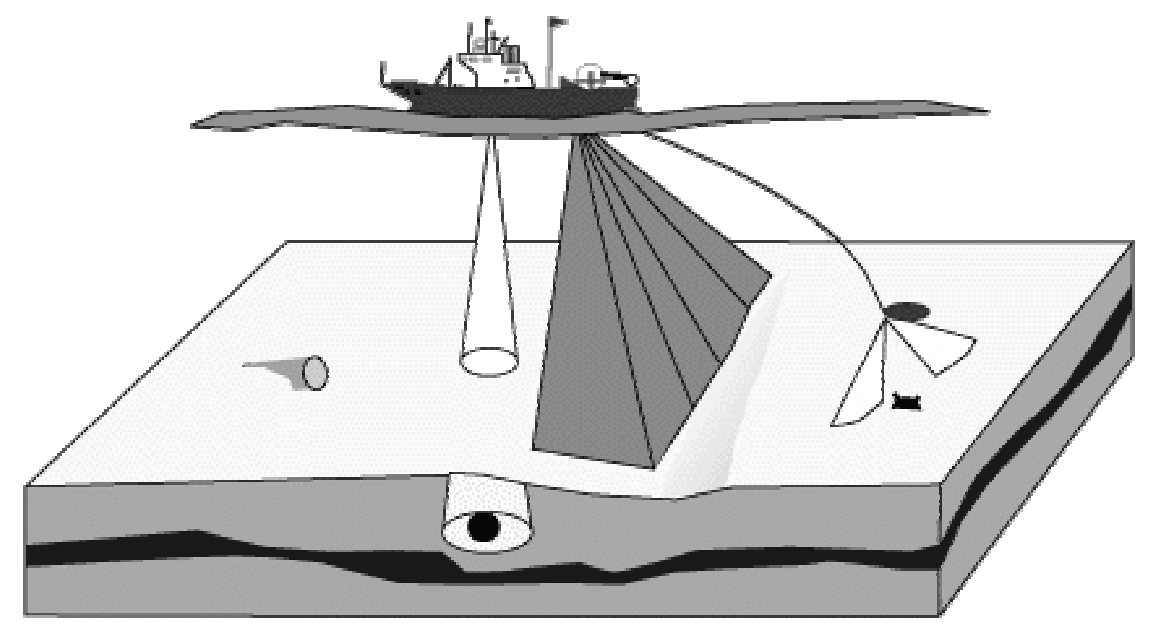

Figure 5. Schematic view of the different acoustic tools: hull-mounted echosounder and multibeam system, deep-towed sidescan sonar. From the European Community ISACS project home page (http://www.isacs.ntnu.no/ISACS).

The information contained in the echo can be compared to theoretical curves corresponding to different types of seafloor, and tempered by such factors as the echosounder directivity pattern and the depth. This is the approach chosen by Pouliquen and Lurton (1992). They integrate the return signal to a certain time, and normalise it by its total value. Their system (patented) recognises seven types of seabed commonly found on the continental shelf: rock, gravel, sand, fine sand, muddy sand, mud and soft mud. Sea trials showed good accuracy, and the maximum depth to which the system has been used is $200 \mathrm{~m}$. Compared to other classification techniques (see below), this approach does not require systematic calibration and/or seafloor sampling before each survey.

The RoxAnn system was developed in the late 1980s, and uses two values derived by the analogue integration of the tail of the first echo and the full extent of the second echo (known as E1 and E2). E1 corresponds to the direct reflection from the seabed, and can be related to its roughness. E2 corresponds to the signal reflected from the sea surface and the seabed again, and can be related to its "hardness" (e.g. Heald and Pace, 1996). Two-dimensional displays of E1 and E2 allow the recognition of the different types of seafloor, whose echoes are clustered together. Commercially available, the RoxAnn system has been used in many surveys in diverse regions. A thorough review of its performance with varying sonar parameters and seabed types can be found, inter alia, in Dyer (2000). The RoxAnn system requires calibration each time it is installed on a new sonar system, even if it has been used in a similar region and with a similar echosounder, but on a different ship. Finally, RoxAnn works by "gating" the incoming signal, i.e. applying a lower and upper threshold to the signal. If these thresholds are inappropriately chosen, the signal loss is irreversible. 

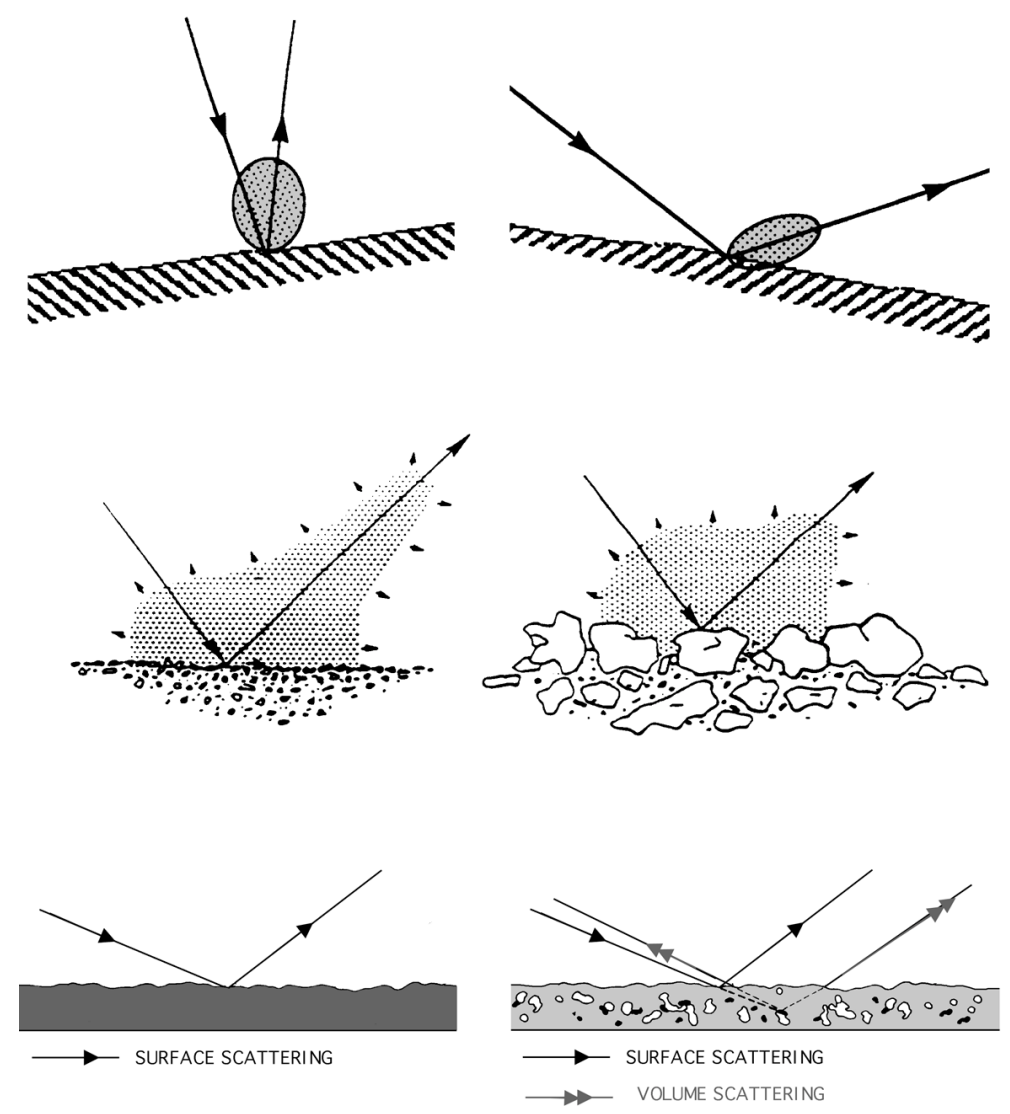

Figure 6. Acoustic scattering is influenced by the geometry of seafloor imaging, and by the intrinsic character of the seafloor (composition, roughness, volume properties), at scales comparable to the acoustic wavelength. From Blondel and Murton, 1997.

Another famous commercial system is QTC-View (e.g. Preston et al., in Zakharia et al., 2000). Developed at the same time than ISAH-S, this system quantifies the shape of each echo with 5 algorithms (histogram, quantile, integrated energy slope, wavelet pack coefficients, spectral coefficients), yielding 166 descriptors of each echo. Principal-Component Analysis reduces this to 3 descriptors, which prove enough to recognise the different types of seafloor. Whenever prior information is available, PCA need not be performed. The recognition of seabed types from the 3 remaining descriptors is achieved through a proprietary algorithm (not disclosed). System calibration needs to be performed before each survey, by collecting a few hundred echoes at sites representative of each bottom type to be mapped (known from in situ sampling). New seabed classes can be recognised during post-processing. QTC-View is also able to recognise subtle differences between sediments, including gas inclusions.

Similar techniques are being developed around the world. One interesting approach includes fractal description of the echo, combined with backscatter strength and the duration of the echo, input into a neural network (Tzegowski and Lubniewski, 2000). Recent developments of "chirp" sub-bottom imaging have been used in basic classification schemes using the sediment impedance profile and attenuation estimation (e.g. LeBlanc et al., 1992), and in later refinements using Biot-StollGassmann models and time-domain inversion algorithms (e.g. Turgut and Wolf, 1998). 
Overall, the classification results can be heavily influenced by the beamwidth and frequency of the echosounder, as well as the sea state (making the echosounder point toward a different seabed patch). The information provided by these echosounders can be quite accurate, but the actual penetration inside the seafloor is not always known, and the footprint covered at each measurement can be quite important.

\subsection{Classification with sidescan sonars}

Sidescan sonars cover a much larger portion of the seabed away from the ship: from a few hundred metres to $60 \mathrm{~km}$ or more (Blondel and Murton, 1997). This coverage is attained by transmitting two broad beams, one on each side (Figure 5). The new sidescan systems can acquire bathymetry as well. Using different frequencies, they can reach resolutions on the seabed of $60 \mathrm{~m}$ down to $1 \mathrm{~cm}$. The images produced can be processed with the arsenal of image classification techniques already developed in the fields of satellite remote sensing, some of which are already applied for optical image classification (cf. Section 3.2). But these techniques must be adapted to the acoustic processes which created these pictures, because the actual backscatter is heavily influenced by the physical processes on the seafloor (Figure 6).
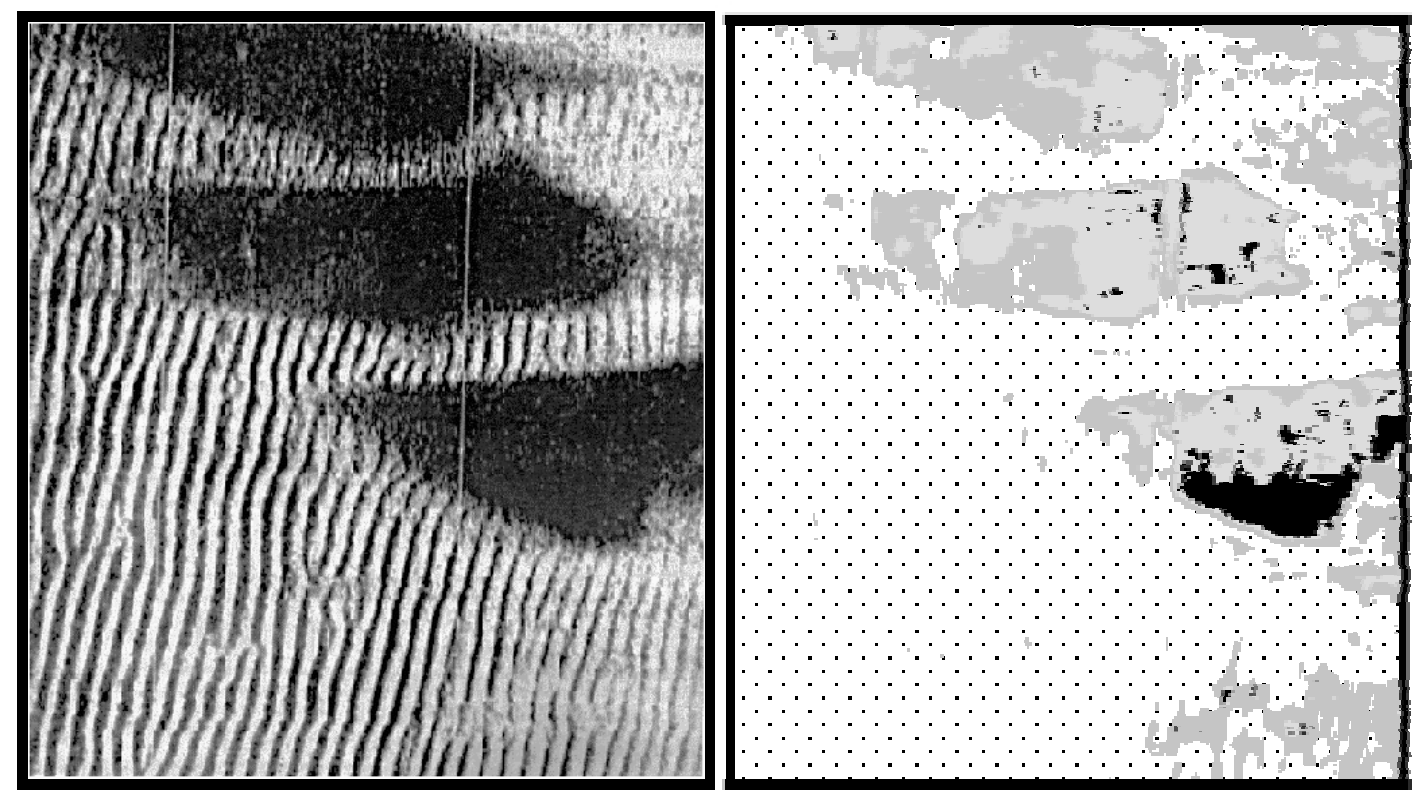

Ripples

Mud (type I)

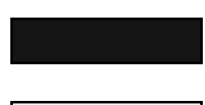

Sediments (type I)

Mud (type II)

Sediments (type II)

Figure 7. Example of seabed classification with TexAn (Blondel, 1999). The image is ensonified from the right, at an altitude of $6 \mathrm{~m}$ above the seafloor, and covers an area approximately $30-\mathrm{m}$ wide. Lighter tones in the original sonar image (left) correspond to higher backscatter levels.

The tonal information (i.e. from the backscatter alone) is a combination of too many factors to be unambiguously interpreted (e.g. Blondel, 1996; Blondel and Murton, 1997). A few studies have endeavoured to use the tonal information alone, in some 
cases with co-registered bathymetry and/or with neural networks, but they were limited to geologically simple terrains, or were of very limited accuracy.

Looking closely at a sonar image (like the one in Figure 7, left), we realise that the information about the type of seabed is in fact mainly conveyed by the texture of the image. This has been confirmed by the theoretical and experimental studies of the last 20 years, presented in Blondel (1996) and Blondel and Murton (1997). Textures can be intuitively described as smooth or rough, small-scale or large-scale, random or organised. The textural properties correspond to the spatial organisation of the grey levels within a neighbourhood. They are best quantified with stochastic methods, such as Grey-Level Co-occurrence Matrices (GLCMs). This forms the basis of the classification software TexAn (e.g. Blondel, 1996; Blondel, 1999).

GLCMs address the average spatial relationships between pixels of a small region, by quantifying the relative frequency of occurrence of two grey levels at a specified distance and angle from each other. More than 25 textural indices have been developed to describe GLCMs. Their usefulness for sonar images has been assessed in detail (e.g. Blondel, 1996; Blondel, 1999), and only two indices have been retained: entropy and homogeneity. Entropy measures the lack of spatial organization inside the region where the GLCM is computed. Entropy is high when all co-occurrence frequencies are equal, i.e. very low. This marks rougher textures. Conversely, entropy is low when the texture is smoother and more homogeneous. Sedimentary facies will show low entropies, increasing with the number of heterogeneities (gravel patches, ripples, rocky outcrops). More complex structures such as slumps or turbidity channels will present higher entropies. All geological features visible on sonar images are characterised by specific entropy signatures. Local-scale variations will also be enhanced by changes in entropy. The other textural parameter, homogeneity, is directly proportional to the amount of local similarities inside the computation window. This parameter was specially modified to ensure its invariance through linear transformations of the grey levels (Blondel, 1996). If the Angle-Varying Gain or Time-Varying Gain are changed during sonar data acquisition, or if the image contrast is changed but the seafloor remains the same, then the modified homogeneity parameter will remain the same. Homogeneity will be higher in regions of homogeneous backscatter or in regions with a few grey levels organised along at the scale of the computation window. Homogeneity is able to quantify the differences between smooth sediments and faulted or deformed areas (including ripples or slumps).

Like the parameters used in RoxAnn or QTC, these two parameters are sufficient to completely classify seabed types, with accuracies ranging between $60 \%$ and $100 \%$ (as measured through intensive and extensive comparison with existing ground truth). The classification algorithm used is called Measurement-Space Guided clustering (Blondel, 1999), and is designed to make maximum use of the interpreter's knowledge, if available. Figure 7 shows a typical application of TexAn, in a region chosen, on purpose, as simple, because of the possibility that finer details might get lost in reproduction. The image on the left was acquired with a 100-kHz sonar (Klein 590), in a water depth of $18 \mathrm{~m}$ in the North Sea. Only very limited processing was performed after the acquisition. The image can be divided into two major elements: dark homogeneous patches of low backscatter and linear parallel backscatter variations. On the basis of their characteristics, and with subsequent ground-truthing (Hühnerbach, pers. comm.), these areas are respectively interpreted as patches of mud, and wave-driven ripples in medium-grained sand, with both bifurcated and regular crests (Milkert and Hühnerbach, in Blondel and Murton, 1997). TexAn maps 
out exactly the different regions of mud and sand ripples, but goes further by detecting other textural variations. Some areas of the sand ripples are less distinct: the ripples may be smaller, or made from a different material. They are located mainly at the proximity of the mud patches, supporting the idea of ripples decreasing in height as the geological setting changes. Similarly, the dark mud patches are in fact composed of distinct regions. The darker tones delimit homogeneous areas where the textures are smoother. Logically, they are located away from the regions where ripples are destroyed or reduced. Finally, the artefacts visible on the image (sub-vertical lines) appear only as slight variations in the textures, but do not influence the final results, nor the geological interpretation.

TexAn has been validated by comparison with ground-truthing at all ocean depths, and for frequencies ranging from $6.5 \mathrm{kHz}$ to $657 \mathrm{kHz}$ (e.g. Blondel, 1996; Blondel, 1999). It was also shown to detect details invisible to the human eye, however trained, because of its physiological limitations (Blondel, 1996). TexAn is hardwareindependent, and can be used at any stage of processing (or non-processing). Contrary to some seafloor characterisation techniques, TexAn does not lose the original information. It is always possible to come back to the original sonar data, and reprocess/reinterpret it. This technique makes most of the user's experience, and with Artificial Intelligence techniques, can build self-learning, self-adapting systems.

Another processing package, called SAPS, is cited for completeness as it includes some sediment classification capabilities based on similar textural analyses. But its applicability to complex terrains or the types of seabeds found in deeper waters of the continental margins has never been tested. From the scarce marketing literature available on the subject, it seems restricted to frequencies of a few tens of kilohertz.

The performance of any classification technique relies heavily on the quality and amount of data processing performed (Blondel and Murton, 1997). One cannot stress enough the progress that could be achieved if all surveying sidescan sonars were properly calibrated, and if the final images were expressing the backscatter in $\mathrm{dB}$ and not relative grey levels. Such progress was seen in satellite imagery, where each pixel in the image corresponds to a well-calibrated reflectance, which can be used in turn to refine the classification accuracy. More sidescan instruments are now delivering highresolution bathymetry, or collecting some kind of underway data (chemical, optical, etc.). This new information should also be added to refined or new classification schemes. The current trend toward standardisation of the processing techniques (see Blondel and Murton, 1997, for details), the systematic calibration of instruments, and the incorporation of sidescan sonar and other data all promise that this field of research will remain open and active in the next decades.

\subsection{Multibeam seabed classification}

Multibeam systems are the latest addition to deep-sea surveying tools. They transmit several beams (up to 120 for some instruments), covering a wide swath (Figure 5). These systems acquire bathymetry for each beam, and backscatter strengths can be derived from the individual measurements. Multibeam systems have proved particularly attractive for the mapping of Exclusive Economic Zones (in particular for their extension beyond the $200 \mathrm{~nm}$-limit, for which bathymetry is paramount), and for repeat surveys of near-shore areas. Addressing the comments made at the end of the previous section, multibeam systems are always calibrated, and the data processing steps are practically standardised. 
Knowledge of the local bathymetry, at each point where backscatter has been acquired, can be used to correct the imagery and represent it using the exact local incidence angles. Analysis of the imagery itself proves different from the sidescan sonar case, partly because the footprint on the seabed is generally much larger $(100 \mathrm{~m}$ compared to a few metres), partly because of the difference in frequency and beam widths. Textural analysis techniques, for example, have not been very successful. Markov Random Fields have met with more success. They are used to partition the backscatter image into regions as close as possible to the geological partition (e.g. Lurton et al., in Pace et al., 1997). Markov fields provide a simple mathematical model of local interactions at the pixel scale. Many types of optimisation algorithms are available in the literature, such as Iterated Conditional Mode (ICM) or simulated annealing. Some of these techniques are now incorporated into IFREMER proprietary software.

A complete suite of different software tools for multibeam data classification has been developed by the Ocean Mapping Group of the University of New Brunswick (Canada). Mayer et al. (in Pace et al., 1997) use waveform characterisation of the vertical incidence measurements, and association with a particular seabed type, either provided by the user or from a waveform dictionary. Alternatively, more refined analysis can be performed on the waveform, and analysed in multivariate space with a graphical tool called Lassoo. This allows to mimic waveform descriptors such as the E1 and E2 parameters used by RoxAnn, or to perform more complex analyses. Hughes-Clarke et al. (in Pace et al., 1997) combine the angular response of the backscattered intensity with information from the local bathymetry. The angular response is characterised based on its mean level, on the slope over pre-defined angular sectors, and on the presence or absence of abrupt changes in the slope. Because the angular response is derived from a finite area, the presence of sediment boundaries must be tested as well. Mitchell and Hughes-Clarke (1994) use a similar technique, adding measurements of topographic curvature to improve the precision. Classification maps generally show a good accuracy. Some of the examples presented in these articles were acquired at an impressive speed of 16 knots, with the Simrad EM-1000 multibeam system.

\section{CONCLUSION}

This article aimed at showing the different tools of seabed classification, and how they had been applied, or could be applied to ocean margins. After a reminder of how varied and complex the ocean margins are, the article proceeded to define seabed classification, its different meanings, and its objectives. The definition chosen here is that seabed classification techniques should achieve at least a basic recognition of the type of seafloor surveyed, or identify a set of intrinsic characteristics from which the type of seafloor could be identified. The more intuitive tools were presented first: in situ analysis, in particular with free-fall instruments; and optical seabed classification, from video or still imagery. Interesting techniques using the chemical characteristics of the seabed, and the differences in $\gamma$ radioactivity, were presented next.

The main part of the article was the review of acoustic classification techniques, by far the most present in the literature. The particularities of acoustic scattering on the seafloor mean that physical processes are more important, and need to be accounted for. Seismic techniques provide some information on the seabed, but have comparatively lower spatial resolutions and do not offer as much field for computerbased seabed classification algorithms. Echosounder-based techniques are more 
promising, and this was seen with the flurry of commercial packages available, of which Roxann and QTC-View are but two examples. Classification of sidescan sonar images has been progressing much in the last decades, in part because of the increase in computer power which allowed to test new or more intensive approaches. The technique presented here (TexAn) has been the most intensively tested, covering the whole ocean depth at frequencies from $6.5 \mathrm{kHz}$ to $675 \mathrm{kHz}$ (spanning two orders of magnitude). Finally, multibeam classification techniques were also presented, with software packages from IFREMER and the University of New Brunswick.

The present article does not aim at being an exhaustive list of classification software and techniques, and their compared merits. Rather, it aims at showing the basic mechanisms by which seafloor classification can be attained, and how its accuracy can be assessed. The examples given throughout the article are far from being the only examples available, and the choice was dictated as much by the proven merits of these systems as by the space available. A whole book would instead be necessary.

The capability and spatial coverage offered by the different classification techniques will vary, depending on the tools and on the applications they are intended for. Some tools will prove very important for large-scale geological studies or EEZ mapping, while others will be more important for marine biology or environmental assessments. Some tools are very accurate, but require extensive calibration and hardware modifications; while others are maybe less accurate, but more user-friendly and simple to deploy.

Seafloor classification is an open and fast-moving field of research. Current trends are based as much on technological improvements as on scientific advances. Some of the developments most likely to impact on future seabed classification are:

- Increasing computer power and storage capabilities, for steadily decreasing costs;

- Addition of underway geophysical or chemical measurements, which might provide additional information about the seabed;

- Increasing use of Artificial Intelligence (such as belief and decision networks) and data mining techniques;

- Use of multi-frequency measurements, for example with parametric arrays (e.g. Caiti et al., in Pace et al., 1997). This creates the potential for multispectral classification as performed so successfully in satellite remote sensing;

- Move toward higher frequencies (1 $\mathrm{MHz}$ and beyond) and therefore higher resolutions on the ground;

- Use of multistatic geometries, where the sonar and one or several receivers are physically decoupled (e.g. Blondel et al., in Zakharia et al., 2000);

- Better understanding of the physical processes behind high-frequency acoustic scattering on the seabed, through theoretical and experimental studies.

Computer-based seabed classification is steadily gaining a foothold in even the more traditional domains of marine surveying. Its reasoned use makes it an invaluable tool to help the human interpreter and the ocean-going scientist, whether they are specialists of the phenomena investigated or not. Seabed classification tools are not primarily intended as substitutes for human interpretation, and they should not be viewed as such. The main powers of decision/interpretation still rest with the scientist. This flexibility, supported by the latest technical advances, guarantees a promising 
future for seabed classification and its applications in multi-disciplinary studies of the ocean margins.

Acknowledgments: I am very grateful to Dr. D. Billett (SOC, UK) and Prof. Dr. G. Wefer (U. Bremen, Germany), for their invitation. I would also like to thank Dr. I. Mehser (Hanse Inst., Germany) and the Hanse 2000 organising committee. Discussions and thorough reviews of this manuscript by Prof. W. Berger (UCSD, USA) and Dr. T.C.E. van Weering (NIOZ, Netherlands) are gratefully acknowledged.

\section{References}

Balsam, W.L., B.C. Deaton, J.E. Damuth; "Evaluating optical lightness as a proxy for carbonate content in marine sediment cores", Marine Geology, vol. 161, no. 2-4, p. 141-153, 1999

Barbagelata, A., M.D. Richardson, B. Miaschi, E. Muzi, P. Guerrini, L. Troiano, T. Akal; "ISSAMS: An in situ sediment geoacoustic measurement system", in Shear waves in marine sediments, J.M. Hovem, M.D. Richardson, R.D. Stoll (eds.), p. 305-312, Kluwer: Dordrecht, 1991

Blondel, Ph.; "Segmentation of the Mid-Atlantic Ridge south of the Azores, based on acoustic classification of TOBI data", in MacLeod, C.J., P. Tyler and C.L. Walker (eds.), Tectonic, magmatic and biological segmentation of mid-ocean ridges, Geol. Soc. Special Pub. 118, p. 17-28, 1996

Blondel, Ph.; "Textural analysis of sidescan sonar imagery and generic seafloor characterisation", J. Acoust. Soc. Am., vol. 105, no. 2, p. 1206, 1999

Blondel, Ph., B.J. Murton; "Handbook of Seafloor Sonar Imagery", PRAXIS: Chichester, 314 pp., 1997

Coles, B.W., W. Radzelovage, P. Jean-Laurant, K. Reihani; “ Processing techniques for multi-spectral laser line scan images”, Proc. IEEE/MTS Oceans'98, 1998

Durham, L.S.; “3-D models are making cents”, AAPG Explorer, November 1999

Dyer, C.M.; "Studies of an acoustic sediment discrimination system", MPhil thesis, 152 pp. University of Bath, 2000

Harsdorf, S., M. Janssen, R. Reuter, B. Wachowicz, R. Willkomm; "Lidar as part of an ROV-based sensor network for the detection of chemical pollutants on the seafloor”, Proc. IEEE/MTS Oceans'98, 1998

Heald, G.J., N.G. Pace; “An analysis of 1st and 2nd backscatter for seabed classification”, ECUA-1996 Proc., p. 649-654, Crete, 1996

Irish, J.L., W.J. Lillycrop; "Scanning laser mapping of the coastal zone: the SHOALS system", ISPRS J. Photogrammetry and Remote Sensing, vol. 54, no. 2-3, p. 123-129, 1999

Juteau, T., R. Maury; “The oceanic crust, from accretion to mantle recycling”, 390 pp., PRAXIS: Chichester, 1999

Kidd, G.D.; "Fundamentals of 3-D seismic visualization”, Sea Technology, vol. 40, no. 9, p. 19-23, 1999

Lebart, K., E. Trucco, D. M. Lane; "Real-time automatic sea-floor change detection from video", Proc. IEEE/MTS Oceans'2000, p. 337-343, 2000

LeBlanc, L.R., L. Mayer, M. Rufino, S.G. Schock, J. King; "Marine sediment classification using the chirp sonar", J. Acoust. Soc. Am., vol. 91, no. 1, p. 107-115, 1992

Liu, H.H., Fu, K.S., "A syntactic pattern recognition approach to seismic discrimination," Geoexploration, vol. 20, p. 183-196, 1982.

de Meijer, R.J., L.B. Venema, J. Limburg; "Synoptical mapping of seafloor sediment", Sea Technology, vol. 41, no. 7, p. 21-24, 2000 
Mitchell, N.C., J.E. Hughes-Clarke; "Classification of seafloor geology using multibeam sonar data from the Scotian Shelf”, Mar. Geol., vol. 121, p. 143-160, 1994

Noakes, J.E., S.E. Noakes, D.K. Dvoracek, P.B. Bush; "Survey and mapping system for surficial marine sediments", Sea Technology, vol. 40, no. 8, p. 49-54, 1999

Pace, N.G., E. Pouliquen, O. Bergem, A.P. Lyons (eds.), High-Frequency Acoustics in Shallow Water, SACLANTCEN Pub., Lerici, Italy, 1997

Pouliquen E, X. Lurton; "Identification of the nature of the seabed using echo sounders", J. Phys., vol. 4, no. 2(C1), p. 941-944, 1992

Rosenberger, A., P. Weidelt, C. Spindeldreher, B. Heesemann, H. Villinger; "Design and application of a new free fall in situ resistivity probe for marine deep water sediments", Marine Geology, vol. 160, no. 3-4, p. 327-337, 1999

Simaan, M.A.; “Texture-based techniques for interpretation of seismic images”, Proc. Oceans'98 MTS/IEEE, 1998

Stoker, M.S., D. Evans, A. Cramp (eds.);“Geological processes on continental margins: sedimentation, mass-wasting and stability”, Geol. Soc. Special Pub. 129, 362 pp., May 1998

Stoll, R.D., T. Akal; "XBP - Tool for rapid assessment of seabed sediment properties", Sea Technology, vol. 40, no. 2, p. 47-51, 1999

Tzegowski, J., Z. Lubniewski; “The use of fractal properties of echo signals for acoustical classification of bottom sediments", Acta Acustica, vol. 86, no. 2, p. 276-282, 2000

Telford, W.M., L.P. Geldart, R.E. Sheriff; "Applied Geophysics”, 2nd edn, 770 pp., Cambridge University Press: Cambridge, 1990

Turgut, A., S.N. Wolf; "Inversion of sediment properties from chirp sonar data using an extended BiotStoll-Gassmann model”, J. Acoust. Soc. Am., vol. 104, no. 3, pt. 2, p. 1788, 1998

Werby, M.F., G.J. Tango, G.E. Ioup; "Remote seismo-acoustic characterization of shallow ocean bottoms using spatial signal-processing of towed array measurements", Geophysics, vol. 51, no. 7, p. 1517,1986

Zakharia, M., P. Chevret, P. Dubail (eds.), Proceedings of the Fifth European Conference on Underwater Acoustics ECUA-2000, 1550 pp., Lyon, France, 2000 